\title{
KAJIAN ASPEK PSIKOLOGI SENAM KESEGARAN JASMANI, SEBUAH STUDI KASUS PADA SENAM KEARIFAN LOKAL
}

\author{
Susy Purnawati ${ }^{1}$, Luh Made Indah $\mathrm{SHA}^{2}$, Luh Putu Ratna Sundari ${ }^{3}$, I D A P Inten \\ Primayanti $^{4}$ \\ 1, 2,3,4 Departemen Ilmu Faal Fakultas Kedokteran Universitas Udayana \\ Email: s_purnawati@yahoo.com
}

\begin{abstract}
Abstrak
Latar Belakang: Emosi atau perasaan pelaku kegiatan olahraga perlu mendapat perhatian karena emosi di samping mempengaruhi aspek-aspek kejiwaan yang lain (akal dan kehendak) juga mempengaruhi aspek fisiologisnya. Metode: Telah dilakukan penelitian awal (preliminary study) yang merupakan studi observasional (cross sectional analitik) pada bulan April 2018 di Denpasar, memadukan pengamatan, hasil wawancara terhadap key informant person (pengumpulan data kualitatif) dan pengumpulan data secara kuantitatif menggunakan kuesioner Task and Ego Orientation in Sport (mixed method). Hasil: penelitian menunjukkan reaksi emosional yang muncul sebagai efek dilakukannya senam Janger kearifan lokal sangat positif. Fokus perhatian pesenam pada gerakan-gerakan senam, iringan gamelan tradisional yang mengingatkan nuansa spiritual serta efek aerobic exercise dalam target zona latihan dapat memberikan rasa gembira dan ketenangan mental. Aktivitas senam dalam kelompok memberi efek terjadinya interaksi sosial yang dapat memunculkan sikap kompetitif. Efek tersebut merupakan efek yang terjadi oleh adanya faktor keberadaan orang lain atau presence of others. Kesimpulan: Senam Janger dari aspek psikologis dapat memberikan efek: reaksi emosi yang positif (gembira, berkurangnya ketegangan), akan tetapi dalam penelitian ini belum bisa dibuktikan efeknya terhadap peningkatan percaya diri dan perasaan unggul dalam berkompetisi mengingat penggunaan sampel yang sangat kecil.
\end{abstract}

Kata kunci: senam umum, aspek psikologi, emosi positif

\section{REVIEW OF PHYSICAL FITNESS GYMNASTICS, A CASE STUDY ON A LOCAL GENIUS GYMNASTICS}

\begin{abstract}
Background: Emotions or feelings among sports participants need to get attention because emotions in addition to affecting other psychological aspects (mind and desire) also affect the physiological aspects. Method: This preliminary study was an observational (cross sectional analytic) study conducted in April 2018 in Denpasar that combined observations, interviews among key informant person (to collect the qualitative data) and quantitative data collection used a Task and Ego Orientation in Sport Questionnaire (mixed method). Result: The results of this study showed an emotional reaction that emerged as the effect of doing Senam Janger exercises was very positively. The focus of attention on gym movements, traditional gamelan accompaniment that reminds spiritual nuances, as well as aerobic exercise effects in the zones target of exercise can provide a sense of excitement and mental calm. The gymnastics activity within group have an effect on social interaction that can lead to
\end{abstract}


competitiveness attitudes. The effect occurs by the presence of other persons factor or presence of others. Conclusion: Senam Janger exercise -from the psychological aspect- create an effect of positive emotional reactions (joy, less tension), but in this study has not been proven its effect on increased confidence and superior feeling in competing due to very small sample size.

Keywords: general gymnastics, psychological aspects, positive emot

\section{LATAR BELAKANG}

Kajian aspek psikologi suatu kegiatan olahraga merupakan hal yang sangat penting. Mengingat masih kurangnya awareness terhadap aspek tersebut di kalangan para pelaku olahraga maupun pelatih, terutama di masyarakat ataupun di sekolahsekolah.

Secara umum, penerapan psikologi dalam bidang olahraga adalah untuk membantu agar bakat olahraga yang ada dalam diri seseorang dapat dikembangkan sebaik-baiknya tanpa adanya hambatan dan faktorfaktor yang ada dalam kepribadiannya. Dengan kata lain untuk membantu seseorang agar dapat menampilkan prestasi yang optimal, yang lebih baik dari sebelumnya ${ }^{1}$. Menurut Weinberg dan Gould (2015), psikologi olahraga mempelajari bagaimana faktor psikologi mempengaruhi performance fisik individu, serta memahami bagaimana partisipasi dalam olahraga dan latihan mempengaruhi perkembangan individu termasuk kesehatan dan kesejahteraan hidupnya ${ }^{2}$. Menurut Kerlinger tingkah laku manusia yang tampak pada hakikatnya tidak terlepas dari sikap (attitude) yang tidak tampak ${ }^{3}$. Dengan memprediksi kemungkinankemungkinan pada atlet yang berkaitan dengan masalah psikologis akan dapat menentukan program-program dan target-target sesuai keadaan dan kemampuan atlet yang bersangkutan serta dapat dihindarkan hal-hal yang kurang menguntungkan perkembangan atlet $^{1}$. Pendapat lainnya diungkapkan oleh Tiihonen, 2003 (dalam Stelter \&
Roesler, 2005) -sehubungan dengan aspek psikologi dalam olahraga, bagaimana gerakan-gerakan tubuh saat berolahraga mempengaruhi mind-, yang menyatakan sebagai berikut ${ }^{4}$.

"How do we explain the timelessness of running for two hours, or the trance one slips into while repeatedly practicing a five-foot put, or a free-throw? How do we make a reader understand what it really means to win or better yet, to lose? How do we convey physical pain? How do we provide readers with a sense of what it's like to be in the groove, such as when a team experiences complete synchronicity almost verging on telepathy? Ironically, sport is arranged linearly but experienced circularly. It's the story of the curved line, the arc, the splash, the whoosh, and it's how this is all experienced and felt that is our job to explain and communicate, and must influence our voice and how we are heard throughout a story. (Tiihonen, 2003)"

Emosi atau perasaan pelaku kegiatan olahraga perlu mendapat perhatian karena emosi di samping mempengaruhi aspek-aspek kejiwaan yang lain (akal dan kehendak) juga mempengaruhi aspek fisiologisnya. Olahraga yang dilakukan sesuai dengan aturan yang benar serta yang dapat memberi efek kegembiraan atau 
perasaan bahagia akan membuat individu untuk mengulangi kembali kegiatan olahraga tersebut. Dengan demikian akan menjadi jaminan tercapainya tujuan melakukan olahraga tersebut (misalnya efek terhadap kebugaran jasmani maupun efek positif lainnya, atau terhadap komponen biomotorik tertentu).

Penjelasan di atas mencerminkan bahwa diperlukan suatu kajian aspek psikologis dari Senam Kearifan Lokal Janger Perdiknas (Senam Janger) yang menjadi dasar alasan diaplikasikannya Senam Janger ini pada masyarakat luas di kemudian hari.

\section{METODE PENELITIAN}

Penelitian awal (preliminary
study) ini
obeservasional analitik) yang memadukan pengamatan, hasil wawancara terhadap key informant person (pengumpulan data kualitatif) dan pengumpulan data secara kuantitatif (pre-posttest one group) menggunakan kuesioner (mixed method). Penelitian dilakukan pada bulan April 2018 di Denpasar. Data kuantitatif diukur menggunakan Task and Ego Orientation in Sport Questionnaire (TEOSQ) ${ }^{5}$ yang telah diterjemahkan dalam bahasa Indonesia untuk menilai self effikasi dalam konteks mastery (task orientated) dan menumbuhkan jiwa kompetisi dalam konteks out performing others (ego orientated). TEOSQ memuat 13 item pernyataan yang dijawab dengan "sangat tidak setuju-skor $=1-$ " sampai "sangat setuju -skor = 5-". Sampel diminta memilih option jawaban tersebut berdasarkan pernyataan "saya merasa paling sukses saat berolahraga ketika: (1). Saya satu-satunya yang bisa melakukannya; (2) Saya belajar sesuatu yang baru dan hal itu membuat saya ingin berlatih lagi; (3) saya bisa melakukannya lebih baik dari orang lain; (4) orang lain tidak bisa melakukannya sebaik saya; (5) saya belajar sesuatu yang menyenangkan untuk dilakukan; (6) orang lain menyerah dan saya tidak; (7) saya belajar sesuatu yang baru dengan keras; (8) saya berusaha dengan giat; (9) saya memberikan nilai target yang tertinggi; (10) sesuai yang saya pelajari membuat saya ingin berlatih lagi; (11) saya yang terbaik; (12) sesuatu yang saya pelajari membuat saya tenang; (13) saya melakukan yang terbaik. Dimensi Task mengacu pada item pernyataan nomor $2,5,7,8,10,12$, dan 13. Sedangkan dimensi Ego mengacu pada pernyataan nomor 1, 3, 4, 6, 9 dan 11. Rerata skor dimensi Task didapat dari skor total dimensi orientasi Task dibagi 7 dan rerata skor dimensi Ego didapat dari skor total dimensi orientasi Ego dibagi 6.

Subjek penelitian adalah 6 orang siswa dan guru (terlatih) yang diminta untuk melakukan sebuah senam (senam kesehatan jasmani yaitu Senam Kearifan Lokal Janger Perdiknas (Senam Janger).

\section{HASIL PENELITIAN DAN PEMBAHASAN}

Senam Janger merupakan senam umum yang mencakup beberapa gerakan seperti senam pada umumnya dengan beberapa gerakan khas meniru tarian Janger Bali yang diiringi dengan musik gamelan tradisional Bali. Senam Janger seperti halnya senam kesegaran jasmani adalah merupakan senam yang tergolong mudah, murah, massal, meriah, dan manfaat. Gerakan-gerakan yang energik, mudah / sederhana untuk dipahami dikombinasikan dengan gerakan-gerakan meniru sebuah tarian akan memberi efek yang sangat baik terhadap aspek psikologis terhadap individu yang mempraktikkan senam janger. Selain gerakan-gerakan yang energik dan aspek kemudahan gerakan, senam janger yang diiringi dengan musik gamelan tradisional aransemen 
lagu "Jangi Janger" dengan aliran techno (yang memadukan alat musik tradisi berupa gamelan dengan musik barat, jenis musik pop ethnic) memberi efek yang sangat positif bagi pelaku senam yang telah memiliki memori tentang keindahan irama gamelan tersebut yang juga memberi efek yang berbeda dibandingkan dengan musik ataupun jenis nada-nada pengiring senam lainnya.

Reaksi emosional yang muncul sebagai efek dilakukannya senam Janger sangat positif. Fokus perhatian pada gerakan-gerakan senam, iringan gamelan tradisional yang mengingatkan nuansa spiritual serta efek aerobic exercise dalam target zona latihan dapat memberikan rasa gembira dan ketenangan mental.

Senam Janger yang merupakan bentuk senam umum yang dilakukan secara berkelompok dapat memberi efek terjadinya interaksi sosial yang dapat memunculkan sikap kompetitif. Efek tersebut merupakan efek yang terjadi oleh adanya faktor keberadaan orang lain atau presence of others.

Mengacu dasar-dasar teori kajian aspek psikologis senam, maka Senam Janger juga dapat memberi efek pengendalian kecemasan, relaksasi mental, pemusatan melalui imagery (pengembangan pengendalian imagery dan khayalan hasil yang positif serta pengembangan

keyakinan/kepercayaan ${ }^{6}$. Selain itu, beberapa efek yang timbul sesuai dengan Martens (1987 dalam Indah dan Supriyadi (2017) seperti: (1) kesenangan, memperoleh kesempatan untuk memenuhi kebutuhan akan suatu aktivitas dan menurunkan ketegangan; (2) bertemu dengan sekelompok orang untuk memenuhi kebutuhan berhubungan dengan orang lain dan menjadi bagian dari kelompok; serta (3) memperlihatkan kemampuannya untuk memenuhi kebutuhan akan merasa berharga, dapat menciptakan maupun meningkatkan motivasi untuk rajin melakukan aktivitas exercise tersebut, dalam hal ini adalah Senam Janger. Karena melakukan Senam Janger dirasakan menyenangkan ${ }^{1}$.

Analisis data responden yang menjawab TEOSQ yang menunjukkan perbedaan skor dimensi Task dan dimensi Ego antara sebelum dan sesudah melakukan senam ditampilkan dalam tabel berikut.

\section{Dimensi Task}

Tabel 1. Hasil analisis statistik dimensi Task sebelum dan sesudah senam menggunakan uji paired sample t-test

\begin{tabular}{ccccc}
\hline Variabel & Rerata & SB & $\begin{array}{c}95 \% \mathrm{CI} \\
\text { Lower } \\
\text { Upper }\end{array}$ & Nilai p \\
\hline $\begin{array}{c}\text { Skor Task pre } \\
(\mathrm{n}=6)\end{array}$ & 4,145 & 0,239 & $-0,314$ & 0,856 \\
$\begin{array}{c}\text { Skor Task } \\
\text { post }(\mathrm{n}=6)\end{array}$ & 4,167 & 0,320 & 0,270 & \\
\hline
\end{tabular}

Hasil analisis dimensi task antara sebelum dan sesudah melakukan senam Janger menunjukkan bahwa rerata skor task sebelum senam 4,145 dengan simpang baku 0,239.
Sedangkan rerata skor sesudah senam Janger 4,167 dengan simpang baku 0,320 . Terdapat perbedaan rerata skor task sebesar 0,012. Analisis bivariate menggunakan paired sample t-test 
didapatkan nilai $\mathrm{p}=0,856$. Hal ini menunjukkan bahwa aspek task yang menggambarkan self efficacy (kepercayaan diri untuk menangani suatu tugas) tidak berbeda bermakna. Hasil analisis tersebut berbeda dengan temuan pada beberapa studi sebelumnya yang menyatakan bahwa senam dapat memberi efek yang positif baik aspek fisik maupun kondisi psikologis terhadap pelakunya serta dapat pengembangan keyakinan/kepercayaan ${ }^{6,7,8}$. Nilai $p$ yang lebih besar dari 0,05 pada analisis dapat terjadi akibat jumlah sampel yang sangat kecil serta perbedaan umur subjek penelitian.

\section{Dimensi Ego}

Tabel 2. Hasil analisis statistik dimensi Ego sebelum dan sesudah senam menggunakan uji paired sample t-test

\begin{tabular}{ccccc}
\hline Variabel & Rerata & SB & $\begin{array}{c}95 \% \text { CI } \\
\text { Lower } \\
\text { Upper }\end{array}$ & Nilai p \\
\hline $\begin{array}{c}\text { Skor Ego pre } \\
(\mathrm{n}=6)\end{array}$ & 3,111 & 0,809 & $\begin{array}{c}-0,585 \\
1,365\end{array}$ & 0,351 \\
$\begin{array}{c}\text { Skor Ego post } \\
(\mathrm{n}=6)\end{array}$ & 2,722 & 0,134 & & \\
\hline
\end{tabular}

Berdasarkan Tabel 2 di atas, rerata skor Ego sebelum senam Janger 3,112 dengan simpang baku 0,809 dan sesudah senam sebesar 2,722 dengan simpang baku 0,134. Terdapat perbedaan skor Ego sebesar 0,389. Hasil analisis statistik menggunakan paired sample t-test didapatkan nilai $\mathrm{p}$ $=0,351$ yang menunjukkan bahwa skor Ego yang menggambarkan tumbuhnya jiwa kompetisi tidak berbeda bermakna. Hasil analisis tersebut berbeda dengan pernyataan Mackenzie (2005) yang menyatakan bahwa olahraga dapat menumbuhkan jiwa out performing others (perasaan unggul dalam berkompetisi $)^{5}$.

\section{Kelemahan Penelitian}

Studi ini memiliki kelemahan yaitu rancangan yang digunakan bukan merupakan sebuah studi clinical trial yang melibatkan kelompok kontrol dan dengan sample size yang sangat terbatas.

\section{SIMPULAN DAN SARAN}

Berdasarkan uraian di atas maka dapat disimpulkan bahwa Senam Janger dari aspek psikologis dapat memberikan efek: reaksi emosi yang positif (gembira, berkurangnya ketegangan), Senam Janger dari aspek psikologis dapat memberikan efek: reaksi emosi yang positif (gembira, berkurangnya ketegangan), akan tetapi dalam penelitian ini belum bisa dibuktikan secara signifikan efeknya terhadap peningkatan percaya diri dan perasaan unggul dalam berkompetisi mengingat penggunaan sampel yang sangat kecil.

Disarankan untuk penelitian lebih lanjut dengan melibatkan jumlah sampel yang lebih besar dan homogen dalam kelompok umur serta mengukur efek senam dalam rentang periode yang lebih panjang dengan rancangan studi eksperimen. 


\section{DAFTAR PUSTAKA}

1. Indah LM SHA dan Supriyadi. 2017. Psikologi Olahraga. Denpasar: Vaikuntha International Publication.

2. Weinberg RS and Gould D. 2015. Foundation of sport and exercise psychology $6^{\text {th }}$ Ed. Champaign, IL: Human Kinetics

3. Kerlinger FN. Advances in applied sport psychology: A review. Rotledge.

4. Stelter RS \& Roessler KK. 2005. New Approaches to Sport and Exercise Psychology. Oxford: Meyer \& Meyer Sport (UK) Ltd.

5. Mackenzie B. 2005. 101 Performance Evaluation Test. London: Electric Word plc. 216217
6. Firmansyah H. 2018. Aspek psikologi dalam olahraga senam. Available from: http//upi.edu/.../ASPEK_PSIKOL OGI_DALAM_SENAM

7. Kamajaya DM, Dantes N, dan Kanca IN. 2013. Pengaruh pelatihan senam kesegaran jasmani 2008 terhadap volume oksigen maksimal ditinjau dari kemampuan awal. E-Journal Program Pascasarjana Universitas Pendidikan Ganesha Program Sudi Penelitian dan Evaluasi Pendidikan. Volume 3.

8. Mylsidayu. 2014. Psikologi Olahraga. Jakarta: PT Bumi Aksara. 